\title{
Cardiovascular Risk Profile of a Young Adult Women Population Assisted in Primary Care
} Tomás de Souza Mello, ${ }^{\circledR}$ Mariana Stutz Klen, ${ }^{\circledR}$ Rafael Bellotti Azevedo, ${ }^{1}$ Fernanda Costa Barradas, ${ }^{\circledR}$ Luiza Araújo Nogueira, ${ }^{\circledR}$ Natália Rossilho Moyses Ushijima, ${ }^{\circledR}$ Rafael Barbosa da Silva Bica, ${ }^{1}$ Elizabeth Silaid Muxfeldt ${ }^{1,2}{ }^{(0}$

Universidade Estácio de Sá, Curso de Medicina Campus Presidente Vargas, Estudo LapARC, Rio de Janeiro, RJ - Brazil Universidade Federal do Rio de Janeiro, Faculdade de Medicina, ${ }^{2}$ Rio de Janeiro, RJ - Brazil

\section{Abstract}

Background: Although cardiovascular disease is a major cause of death among women, cardiovascular risk assessment in young women is frequently postponed due to a number of factors.

Objectives: To assess cardiovascular risk of young adult women living in one of Rio de Janeiro's Family Health Strategy geographical units in the city's central area.

Materials and Methods: populational, cross-sectional study with adults between 20 and 50 years old. Sociodemographic characteristics such as educational level and employment status were recorded. Anthropometric measurements, traditional cardiovascular risk factors, gynecological and gestational history, and selected laboratory exams were assessed. The bivariate analysis compared the baseline characteristics of the population between genders and the prevalence of cardiovascular risk factors in women according to educational level and occupation status, using non-paired Student's t-test for normal continuous variables, Mann-Whitney test for asymmetrical continuous variables, and chi-square test for categorical variables. A significance level of $5 \%(p<0.05)$ was adopted.

Results: A total of 710 individuals were enrolled. In women, who comprised 59.7\% of our sample, central obesity and a sedentary lifestyle were more prevalent, whereas smoking and hypertension were less observed. However, women with lower educational status had a higher prevalence of smoking and hypertension. In hypertensive women, factors such as early menopause, higher prevalence of hypertensive disorders of pregnancy and higher number of pregnancies were noticed.

Conclusion: An adverse cardiovascular risk profile in our population of young women was particularly influenced by central obesity, sedentary lifestyle, hypertensive disorders of pregnancy and lower educational status.

Keywords: Cardiovascular Diseases; Risk Factors; Young Adults; Women; Primary Health Care.

\section{Introduction}

Cardiovascular $(\mathrm{CV})$ diseases are the major cause of women mortality: around 8.5 million deaths every year ${ }^{1}$, which increases the demand for prevention strategies that take into account the particularities of its evolution. ${ }^{2,3} \mathrm{CV}$ risk assessment in women involves not only traditional risk factors, but specific ones (gestational complications and hormonal alterations), as well as those that have a higher impact on women's health, such as autoimmune and psychiatric diseases. ${ }^{3}$ Regarding traditional risk factors, it must also be considered that they have different impacts on women.., 5

We know that women's CV risk increases in the postmenopausal period when she loses her hormonal

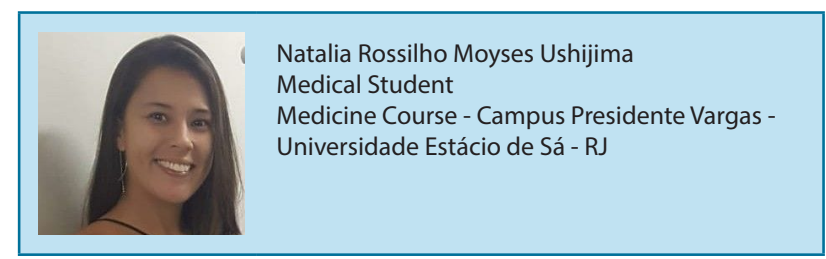


protection. However, CV health of younger women is still less focused on the main studies: current concepts are based on findings in men and older women. The lack of specific approaches for younger women causes flaws in diagnosis, follow-up and treatment, and, consequently, worse outcomes. ${ }^{4-6}$

Considering the deficit of women's CV risk analysis, the objective of our study is to assess the cardiovascular risk profile of young women between 20 and 50 years old who live in the coverage area of Family Health Strategy - Lapa Health-School Center unit, in the Rio de Janeiro city center - LapARC study.

\section{Methodology}

Study design: A population, cross-sectional study from LapARC study cohort (population study of CV risk assessment) included adults between 20 and 50 years old who live in Rio de Janeiro city center, coverage area of Family Health Strategy - Lapa Health-School Center (CSELapa) unit. Until now, 65\% (710 individuals) of the target population (1,100 individuals) have been assessed.

Data collection: Sociodemographic data were recorded, including gender, age, education (illiterate, middle school, high school, and graduate/postgraduate), and current occupation (formal or informal work, unemployed, housewife and student). The low education was defined as middle school, and we have considered unemployed, stayat-home and student as people outside the labor market. Weight (in kg) and height (in meters) were measured using a digital scale and stadiometer to calculate body mass index (BMI) through the formula BMI = weight $(\mathrm{kg}) /$ height $(\mathrm{m})^{2}$. It was performed the measurement of waist circumference using an anthropometric tape measure. Individuals with BMI $>30 \mathrm{~kg} / \mathrm{m}^{2}$ were considered obese and with BMI between 25.1 and $30 \mathrm{~kg} / \mathrm{m}^{2}$ were considered overweight. Central obesity was defined as waist circumference $>88$ $\mathrm{cm}$ in women and $>102 \mathrm{~cm}$ in men. CV risk factors were assessed by standardized questionnaires. Individuals who have smoked in the last 6 months were considered smokers, and those who have not exercised regularly for at least 150 min per week were considered sedentary. Family history of $\mathrm{CV}$ diseases is defined as a patient with coronary or cerebrovascular disease in $1^{\text {st }}$ degree relatives (women under 65 and men under 55 years old). ${ }^{7}$

The diagnosis of hypertension was based on the average of two office blood pressure (BP) measurements with a digital oscillometric device (MicrolifeWatch BP03) with a cuff suitable for arm circumference, according to the Brazilian Guideline of Arterial Hypertension - 2020. ${ }^{7}$ Patients were considered hypertensive with average office BP equal or higher than $140 \times 90 \mathrm{mmHg}$ or when regularly using anti-hypertensive drugs. Participants underwent Home Blood Pressure Monitoring (HBPM) (HEM-705 CP, Omron Healthcare, Kyoto, Japan), using a 7-day protocol in two morning and two afternoon measurements. The measurements of the first day were discarded and the average of the six remaining days was calculated, being considered exams with at least 12 valid measurements. The considered reference value was lower than 135x85 mmHg. ${ }^{8}$

Metabolic alterations were diagnosed by anamnesis (use of hypoglycemic agents and statins) and laboratory exams performed during fasting. We considered fasting glycemia between 100 and $125 \mathrm{mg} / \mathrm{dl}$ as glucose intolerance (GI) and above $126 \mathrm{mg} / \mathrm{dl}$ as diabetes mellitus (DM). To diagnose dyslipidemia, the values considered were total cholesterol above $190 \mathrm{mg} / \mathrm{dl}$, HDL below $40 \mathrm{mg} / \mathrm{dl}$, LDL above $130 \mathrm{mg} /$ $\mathrm{dl}$ and triglycerides above $150 \mathrm{mg} / \mathrm{dl} .{ }^{9}$ Serum creatinine was also measured. Metabolic syndrome was defined as central obesity (waist circumference $\geq 80 \mathrm{~cm}$ in women or $\geq 94 \mathrm{~cm}$ in men) + two of the following criteria (TG $\geq 150 \mathrm{mg} / \mathrm{dl}$, HDLcholesterol $<40 \mathrm{mg} / \mathrm{dl}$ in men and $<50 \mathrm{mg} / \mathrm{dl}$ in women, glycemia $\geq 100 \mathrm{mg} / \mathrm{dl}$ and systolic $\mathrm{BP} \geq 130 \mathrm{mmHg}$ and diastolic $\mathrm{BP} \geq 85 \mathrm{mmHg}$ or use of anti-hypertensive drugs). ${ }^{10}$

Information about gynecological history was also obtained: age of menarche and (when applicable) menopause, regular use of oral or injectable contraceptive drugs, gestational history, occurrence of hypertensive disorders of pregnancy (HDP), and early menopause (before the age of 40).

Data analysis: The statistical analysis was performed using SPSS 19.0 software (SPSS, Chicago, IL, USA). Data normality was verified via histogram and Q-Q plot. Continuous variables were expressed in means and standard deviations when they presented a normal distribution and expressed in median and interquartile range in the case of asymmetrical distribution. The categorical variables were expressed in the number of individuals (n) and percentages. The bivariate analysis compares men and women through non-paired Student's t-test (normal continuous variables), Mann-Whitney test (asymmetrical continuous variables), and chi-square test (categorical variables). A significance level adopted of $5 \%(\mathrm{p}<0.05)$ was adopted. The same method was used to assess the prevalence of cardiovascular risk factors in women according to educational level and occupation.

Through multiple logistic regression, independent correlations for female sex, low education, and occupation 
were assessed as dependent variables. The candidate variables for the models were age, smoking, sedentary lifestyle, obesity, central obesity, hypertension, dyslipidemia, alteration of glycemic profile (DM or GI), and metabolic syndrome. A step-by-step procedure was used to select the independent covariables ( $p<0.10$ was necessary to enter and stay in the model). The HosmerLemeshow goodness-of-fit test and an estimated probability of the area under the ROC curve were used to assess calibration and discrimination of models. The results were presented as an odds ratio and confidence interval (CI) of $95 \%$.

Ethical considerations: The study was approved by UNESA's Research Ethics Committee (number 1.389.191 in 01/15/2016 - CAAE 50605215.4.0000.5284) and the participants signed a Free and Informed Consent Term in accordance with Resolution 466/2012.

\section{Results}

A total of 710 individuals were assessed, being 424 (59.7\%) women, with an average age of $36.5 \pm 9.0$ years. The most prevalent $\mathrm{CV}$ risk factors in the population were dyslipidemia (65.6\%), sedentary lifestyle (44.4\%), overweight (38.7\%), obesity ( $25.2 \%)$, and hypertension (24.8\%). (Table 1 )

Among women, it is worth noticing the prevalence of dyslipidemia (63.9\%), sedentary lifestyle (48.1\%), and central obesity (48.6\%). In figure 1 , we observe that $77 \%$ of women presented $\mathrm{CV}$ risk factors and $12 \%$ of them had three or more risk factors.

When comparing both genders, women presented a higher prevalence of central obesity and sedentary lifestyle. On the other hand, they had lower levels of smoking and hypertension, with significantly lower office BP and HBPM levels. (Table 1) The main association between CV risk factors and female gender was a sedentary lifestyle, and central obesity, which presented an OR approximately 4.5 times higher than the sedentary lifestyle. (Table 2)

Current hypertension diagnosis was significantly higher not only among women with previous history of HDP ( $28.2 \%$ vs $8.4 \%$ ), but also in those who presented early menopause ( $14.1 \%$ vs $4.3 \%$ ). The diagnosis of hypertension was lower among nulliparous ( $20.5 \%$ vs $42.5 \%$ ) without the influence of contraceptive use. (Table 3).

Tables 4 to 7 related education and occupation data. Comparing each educational level and occupation status with the total population of women, we observed that functionally illiterate women $(10 \%)$ had higher prevalence of smoking, obesity, central obesity, hypertension, dysglycemia and metabolic syndrome, although being less sedentary. (Table 4). Low education tripled the risk of smoking and doubled the risk of hypertension, however reducing the risk of sedentary lifestyle. (Table 5) In its turn, the lack of labor market insertion reduced the risk of dyslipidemia, while formal employment reduced the risk of smoking. (Table 7).

\section{Discussion}

Despite women in pre-menopause knowingly presenting a lower $\mathrm{CV}$ risk, few studies assess women in this age range. ${ }^{11}$ Our population study is one of the first studies to assess $\mathrm{CV}$ risk in women under the age of 50 . It demonstrates that those women present higher prevalence of central obesity and are more sedentary. On the other hand, they smoke less and present lower BP levels as well as a more favorable lipid profile. In its turn, low-educated women present higher risk of smoking and hypertension, however having a lower risk of being sedentary.

\section{Primary CV prevention in young women}

Evidenceshows that beforemenopause, higherlevels of sex hormones, such as estradiol, give women a certain protection against $\mathrm{CV}$ diseases ${ }^{12-14}$ through several mechanisms. However, after menopause this 'cardioprotective' effect reduces gradually and $\mathrm{CV}$ morbimortality becomes similar between men and women with ageing. ${ }^{11,15}$ Despite that, there is no evidence of the benefits of hormonal therapy after menopause ${ }^{16}$ to prevent $\mathrm{CV}$ diseases, although the subject is still controversial. ${ }^{17}$

Considering the high CV morbimortality in women and the increase of its prevalence after menopause ${ }^{5,12}$, it is fundamental to stratify the CV risk and adopt primary prevention measures in adult women during her reproductive life. ${ }^{11}$ In our study, most of the women between 20 and 50 years old have already presented one or more traditional CV risk factors (Figure 1). Considering young adults, most of them in the fertile age, data reinforce the importance of an individualized approach - both of each patient and of the comorbidities they present - to guarantee effective, durable benefits.

\section{Traditional risk factors}

Although there are still controversies about obesity and overweight being independent risk factors for $\mathrm{CV}$ diseases ${ }^{18}$, its role in decompensating other 
Table 1 - Baseline characteristics of total population, classified according to gender

\begin{tabular}{|c|c|c|c|c|}
\hline Characteristics & $\begin{array}{c}\text { Total } \\
\text { population } \\
(\mathrm{n}=710)\end{array}$ & $\begin{array}{l}\text { Female } \\
(n=424)\end{array}$ & $\begin{array}{c}\text { Male } \\
(n=286)\end{array}$ & p-value \\
\hline Age, years & $36.5 \pm 9.0$ & $36.7 \pm 8.9$ & $36.1 \pm 9.2$ & 0.420 \\
\hline \multicolumn{5}{|l|}{ Anthropometric measures } \\
\hline BMI. kg/m² & $27.3 \pm 5.4$ & $27.3 \pm 5.7$ & $27.3 \pm 4.9$ & 0.932 \\
\hline Obesity $^{1}, \mathrm{n}(\%)$ & $179(25.2)$ & $108(25.5)$ & $71(24.8)$ & 0.930 \\
\hline Overweight ${ }^{1}, \mathrm{n}(\%)$ & $275(38.7)$ & $154(36.3)$ & $121(42.3)$ & 0.116 \\
\hline Central obesity ${ }^{2}, \mathrm{n}(\%)$ & $279(39.3)$ & $206(48.6)$ & $73(25.5)$ & $\mathrm{p}<0.001$ \\
\hline \multicolumn{5}{|l|}{ Cardiovascular risk factors } \\
\hline Family history of precocious CVD. n(\%) & $231(32.5)$ & $145(34.2)$ & $86(30.1)$ & 0.254 \\
\hline Physical inactivity, n(\%) & $315(44.4)$ & $204(48.1)$ & $111(38.8)$ & 0.017 \\
\hline Smoking, $\mathrm{n}(\%)$ & $109(15.4)$ & $52(12.3)$ & $57(19.9)$ & 0.008 \\
\hline Hypertension, n(\%) & $157(24.8)$ & $76(19.9)$ & $81(32.4)$ & $\mathrm{p}<0.001$ \\
\hline Dyslipidemia, n(\%) & $466(65.6)$ & $271(63.9)$ & $195(68.2)$ & 0.260 \\
\hline Diabetes, $\mathrm{n}(\%)$ & $26(3.7)$ & $15(3.5)$ & $11(3.8)$ & 0.841 \\
\hline Glucose intolerance, $\mathrm{n}(\%)$ & $57(8.0)$ & $37(8.7)$ & $20(7.0)$ & 0.482 \\
\hline Metabolic Syndrome, n(\%) & $128(18.0)$ & $72(17.0)$ & 56 (19.6) & 0.426 \\
\hline \multicolumn{5}{|l|}{ Blood pressure, $\mathrm{mmHg}$} \\
\hline \multicolumn{5}{|l|}{ Office } \\
\hline Systolic BP, mmHg & $122 \pm 16$ & $118 \pm 15$ & $128 \pm 15$ & $\mathrm{p}<0.001$ \\
\hline Diastolic BP, mmHg & $76 \pm 11$ & $75 \pm 10$ & $78 \pm 11$ & $\mathrm{p}<0.001$ \\
\hline Uncontrolled BP, n(\%) & $97(15.3)$ & $36(9.4)$ & $61(24.4)$ & $\mathrm{p}<0.001$ \\
\hline$H B P M(\mathrm{n}=470)$ & & $(\mathrm{n}=291)$ & $(\mathrm{n}=179)$ & \\
\hline Systolic BP, mmHg & $121 \pm 13$ & $117 \pm 12$ & $126 \pm 12$ & $\mathrm{p}<0.001$ \\
\hline Diastolic BP, mmHg & $75 \pm 10$ & $74 \pm 10$ & $76 \pm 9$ & 0.011 \\
\hline Uncontrolled HBPM, n(\%) & $91(19.4)$ & $48(16.5)$ & $43(24.0)$ & \\
\hline \multicolumn{5}{|l|}{ Laboratory exams } \\
\hline Glycemia, mg/dL & $90 \pm 15$ & $90 \pm 15$ & $91 \pm 14$ & 0.840 \\
\hline Creatinine, mg/dL & $0.75 \pm 0.20$ & $0.69 \pm 0.17$ & $0.84 \pm 0.22$ & $\mathrm{p}<0.001$ \\
\hline Cholesterol, mg/dL & $188 \pm 45$ & $191 \pm 46$ & $183 \pm 43$ & 0.069 \\
\hline HDL-cholesterol, mg/dL & $55 \pm 10$ & $56 \pm 10$ & $53 \pm 11$ & 0.021 \\
\hline LDL-cholesterol, mg/dL & $108 \pm 40$ & $111 \pm 39$ & $104 \pm 40$ & 0.093 \\
\hline Triglycerides, mg/dL & $125 \pm 70$ & $123 \pm 73$ & $128 \pm 64$ & 0.511 \\
\hline $\begin{array}{l}{ }^{1} \text { Obesity: } B M I>30 \mathrm{~kg} / \mathrm{m}^{2} / \text { Overweight: } B M \\
{ }^{2} \text { Central Obesity: women }>88 \mathrm{~cm} \text { and men } \\
\text { BMI: Body Mass Index; } C V D \text { : cardiovascula } \\
\text { Values are averages } \pm S D \text { (continuous variab } \\
\text { The bivariate analysis compares men and won }\end{array}$ & $\begin{array}{l}25.1 \text { and } 30.0 \\
\text { BP: blood pre } \\
\text { solute numbers } \\
\text { gh non-paired S }\end{array}$ & $\begin{array}{l}\text { : Home Blood } \\
\text { ges (categoric } \\
\text { t normal con }\end{array}$ & toring. & \\
\hline
\end{tabular}




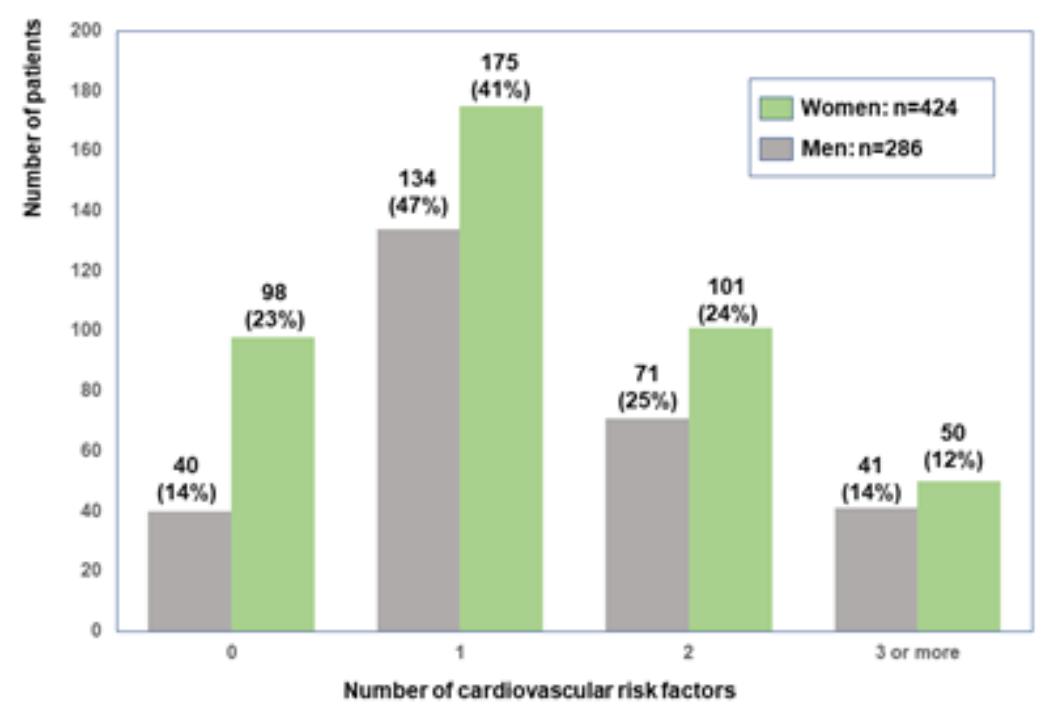

Figure 1 - Number of cardiovascular risk factors classified according to gender.

Table 2 - Logistic regression for cardiovascular risk factors in women, adjusted for age

\begin{tabular}{lcc}
\hline Cardiovascular risk factors & $\begin{array}{c}\text { Women } \\
\text { OR (CI 95\%) }\end{array}$ & p value \\
\hline Smoking & $0.56(0.36-0.87)$ & 0.009 \\
\hline Physical inactivity & $1.50(1.08-2.09)$ & 0.015 \\
\hline Obesity & $0.32(0.18-0.54)$ & $<0.001$ \\
\hline Central obesity & $6.83(4.06-11.50)$ & $<0.001$ \\
\hline Hypertension & $0.32(0.20-0.51)$ & $<0.001$ \\
\hline Dyslipidemia & $0.83(0.59-1.19)$ & 0.317 \\
\hline Adverse glycemic profile & $1.01(0.59-1.62)$ & 0.970 \\
\hline Metabolic Syndrome & $0.95(0.55-1.62)$ & 0.841 \\
\hline Hosmer-Lemeshow goodness-of-fit test: $p=0.604$. Area under the ROC curve: $0.791(95 \%$ IC $0.745-0.838)$ & \\
\hline
\end{tabular}

well-established risk factors, such as dyslipidemia, hypertension and DM, is consensual. ${ }^{19}$

The prevalence of obesity is increasing in the Brazilian population and, among women, it is worth mentioning the increase in the pattern of central obesity, which is more related to $\mathrm{CV}$ risk. ${ }^{20}$ This phenomenon seems to be related to social issues that impact women differently, such as urban violence ${ }^{21}$, double shift work, and household chores. ${ }^{22}$ However, it must be highlighted that indexes and cutting points to identify central obesity in Brazil are not consensual ${ }^{23}$, and discrimination of these levels by ethnicity (white, brown and black people) seems to be needed to several CV risk factors ${ }^{24}$, although being complex.

Nevertheless, the results of our study reflect this problem, showing similar and increased levels of obesity and overweight in both genders. Still, it draws special attention to the high prevalence of central obesity in women, which is directly related to a high CV risk. The data reinforce the need to develop public policies to prevent obesity in general and others with focus on central obesity in female patients. ${ }^{3,5,19,20}$ 
Table 3 - Risk factors related to the gynecological history for hypertension in women

\begin{tabular}{|c|c|c|c|c|}
\hline & $\begin{array}{l}\text { Total women } \\
\quad(n=424)\end{array}$ & $\begin{array}{l}\text { Hypertension } \\
(\mathrm{n}=78)\end{array}$ & $\begin{array}{l}\text { Normotension } \\
\quad(n=346)\end{array}$ & p-value \\
\hline Menarche age, median[IQR] & $13[11-14]$ & $12[11.0-14.0]$ & 13 [11.3-14.0] & 0.769 \\
\hline Contraceptives, n(\%) & $126(29.7)$ & $20(25.6)$ & $108(30.6)$ & 0.414 \\
\hline Hypertensive disorders of pregnancy, n(\%) & $51(12.0)$ & $22(28.2)$ & $29(8.4)$ & $\mathrm{p}<0.001$ \\
\hline Precocious menopause, $\mathrm{n}(\%)$ & $28(6.1)$ & $11(14.1)$ & $15(4.3)$ & 0.003 \\
\hline HRT, n(\%) & $10(2.4)$ & $2(2.6)$ & $8(2.3)$ & 1.00 \\
\hline Nulliparous, n(\%) & $163(38.4)$ & $16(20.5)$ & $147(42.5)$ & $\mathrm{p}<0.001$ \\
\hline N. pregnancies, median [IQR] & $2[1-3]$ & $2[1-3]$ & $1[0-2]$ & $\mathrm{p}<0.001$ \\
\hline
\end{tabular}

Table 4 - Prevalence of cardiovascular risk factors in women according to educational level

\begin{tabular}{|c|c|c|c|c|c|}
\hline Cardiovascular risk factors & $\begin{array}{c}\text { Total } \\
\text { population } \\
(n=424)\end{array}$ & $\begin{array}{c}\text { Functional } \\
\text { illiterate } \\
(n=42)\end{array}$ & $\begin{array}{c}\text { Middle } \\
\text { education } \\
(n=46)\end{array}$ & $\begin{array}{l}\text { High school/ } \\
\text { Technical } \\
\text { course }(n=207)\end{array}$ & $\begin{array}{c}\text { Graduation/ } \\
\text { Post-graduation } \\
(n=129)\end{array}$ \\
\hline Physical inactivity, n(\%) & $204(48.1)$ & $11(26.2)+$ & $19(41.3)$ & $100(48.3)$ & $74(57.4)^{*}$ \\
\hline Smoking, n(\%) & $52(12.3)$ & $11(26.2)^{*}$ & $10(21.7) *$ & $21(10.1)$ & $10(7.8)^{*}$ \\
\hline Obesity, n(\%) & $107(25.2)$ & $17(40.5)^{*}$ & $13(28.3)$ & $50(24.2)$ & $27(20.9)$ \\
\hline Central obesity, n(\%) & $206(48.6)$ & $29(69.0)+$ & $26(56.5)$ & $96(46.4)$ & $55(42.6)$ \\
\hline Hypertension, n(\%) & $78(18.4)$ & $16(38.1)+$ & $12(26.1)$ & $33(15.9)$ & $17(13.2)$ \\
\hline Dyslipidemia, n(\%) & $271(63.9)$ & $32(76.2)$ & $30(65.2)$ & $128(61.8)$ & $81(62.8)$ \\
\hline Adverse glycemic profile, $\mathrm{n}(\%)$ & $52(12.3)$ & $11(26.2)^{*}$ & $3(6.5)$ & $23(11.1)$ & 15 (11.6) \\
\hline Metabolic Syndrome, n(\%) & $72(17.0)$ & $17(40.5) \ddagger$ & $10(21.7)$ & $30(14.5)$ & $15(11.6)$ \\
\hline
\end{tabular}

Regarding dyslipidemia, although young women have a comparatively favorable profile, this tends to be reverted after menopause ${ }^{24,25}$ with evidence that between 50 and 79 years old its prevalence becomes higher in women. ${ }^{26}$ The criteria for drug therapy indication are the same. However, women receive it less frequently and are more prone to refuse and abandon treatment. ${ }^{3,24}$ Thus, improvements in identifying this issue and following it up are fundamental to ameliorate the prognosis.
In our study, the extremely high prevalence of dyslipidemia in young adults (Table 1 ) demonstrates that this is as a primary issue of public health and reinforces the need to identify it and establish an early control. In both genders, besides drug therapy (when needed), counseling actions about healthy habits, such as balanced nutrition, weight control and regular exercises, are fundamental. $2,7,9,10,19$

The association between glycemic profile and CV risk is well established for both genders. ${ }^{2,19,27}$ However, its 
Table 5 - Logistic regression for cardiovascular risk factors and low education in women adjusted for age

\begin{tabular}{llc}
\hline Cardiovascular risk factor & $\begin{array}{c}\text { Women } \\
\text { OR (IC 95\%) }\end{array}$ & p value \\
\hline Smoking & $3.25(1.70-6.20)$ & $<0.001$ \\
\hline Physical inactivity & $0.46(0.28-0.77)$ & 0.003 \\
\hline Obesity & $1.08(0.57-2.03)$ & 0.818 \\
\hline Central obesity & $1.72(0.94-3.13)$ & 0.080 \\
\hline Hypertension & $2.38(1.33-4.29)$ & 0.004 \\
\hline Dyslipidemia & $1.29(0.76-2.21)$ & 0.350 \\
\hline Adverse glycemic profile & $1.06(0.52-2.15)$ & 0.872 \\
\hline Metabolic Syndrome & $1.24(0.59-2.60)$ & 0.566 \\
\hline $\begin{array}{l}\text { Hosmer-Lemeshow goodness-of-fit test: } p=0.632 . \text { Area under the ROC curve: } 0.784(95 \% \text { IC } 0.739-0.846) \\
\text { Obs: Low education included those who studied until completing middle education }(n=88)\end{array}$ & \\
\hline
\end{tabular}

\begin{tabular}{|c|c|c|c|c|c|c|}
\hline Cardiovascular risk factors & $\begin{array}{l}\text { Total } \\
\text { population } \\
(n=424)\end{array}$ & $\begin{array}{c}\text { Formal job } \\
\quad(n=208)\end{array}$ & $\begin{array}{l}\text { Informal job } \\
\qquad(n=65)\end{array}$ & $\begin{array}{l}\text { Unemployed } \\
(n=81)\end{array}$ & $\begin{array}{c}\text { Housewife } \\
(n=26)\end{array}$ & $\begin{array}{c}\text { Student } \\
(\mathrm{n}=44)\end{array}$ \\
\hline Physical inactivity, n(\%) & $204(48.1)$ & $97(46.6)$ & $29(44.6)$ & $41(50.6)$ & $10(38.5)$ & $27(61.4)^{*}$ \\
\hline Smoking, $\mathrm{n}(\%)$ & $52(12.3)$ & $19(9.1)^{*}$ & $15(23.1)+$ & $9(11.1)$ & $6(23.1)$ & $3(6.8)$ \\
\hline Obesity, n(\%) & $107(25.2)$ & $57(27.4)$ & $16(24.8)$ & $23(28.4)$ & $8(30.8)$ & $3(6.8)+$ \\
\hline Central obesity, $\mathrm{n}(\%)$ & $206(48.6)$ & $106(51.0)$ & $32(49.2)$ & $40(49.4)$ & $15(57.7)$ & $13(28.5)^{*}$ \\
\hline Hypertension, $\mathrm{n}(\%)$ & $78(18.4)$ & $37(17.8)$ & $13(20.0)$ & $16(19.8)$ & $8(30.8)$ & $4(9.1)$ \\
\hline Dyslipidemia, n(\%) & $271(63.9)$ & $137(65.9)$ & $44(67.7)$ & $41(50.6)+$ & $18(69.2)$ & $31(70.5)$ \\
\hline Adverse glycemic profile, $\mathrm{n}(\%)$ & $52(12.3)$ & $29(13.9)$ & $10(15.4)$ & $6(7.4)$ & $4(15.4)$ & $3(6.8)$ \\
\hline Metabolic Syndrome, n(\%) & $72(17.0)$ & $42(20.2)$ & $11(16.9)$ & $11(13.6)$ & $6(23.1)$ & $2(4.5)^{*}$ \\
\hline \multicolumn{7}{|c|}{$\begin{array}{l}\text { * } p<0.05 ;+p<0.01 ; \neq p<0.001 \\
\text { The categorical variables were expressed in the number of individuals }(n) \text { and percentages. } \\
\text { The bivariate analysis compares each occupation status through chi-square test (categorica }\end{array}$} \\
\hline
\end{tabular}

influence seems to be greater in women. In non-diabetic populations, CV complications are more prevalent among men in every age range, except in very elderly individuals. In patients with DM, such differences are reduced $^{28}$, suggesting that the disease counters the cardioprotective effect of female sex hormones in premenopause. ${ }^{29}$ The higher relative risk of $\mathrm{CV}$ mortality in women with diabetes may be related, among other hypotheses, to earlier insulin resistance ${ }^{3-5}$ and a higher average BMI when DM is diagnosed. ${ }^{27}$
In our study, the prevalence of GI and DM were low and similar between men and women (Table 1), possibly due to the young cohort. Despite that, it is important to remember that more unfavorable outcomes in young women will demand more attention to this group, both in monitoring and possible interventions. ${ }^{2,19}$

Regarding hypertension, our results were similar to those achieved in other studies in Brazil ${ }^{30}$ and worldwide. ${ }^{31,32}$ Data suggest that women in this age range are less prone to develop hypertension, a disease that 
Table 7 - Logistic regression for cardiovascular risk factors in women out-of-work and those in formal job

\begin{tabular}{lcc}
\hline Cardiovascular risk factor & $\begin{array}{c}\text { Women outside labor market } \\
\text { OR (IC 95\%) } \\
(\mathbf{n}=\mathbf{1 5 1})\end{array}$ & $\begin{array}{c}\text { Women with formal job } \\
\text { OR (IC 95\%) } \\
(\mathbf{n}=\mathbf{2 0 8})\end{array}$ \\
\hline Smoking & $1.35(0.70-2.61)$ & $0.53(0.29-0.97) £$ \\
\hline Physical inactivity & $0.97(0.62-1.51)$ & $0.88(0.60-1.29)$ \\
\hline Obesity & $1.34(0.73-2.46)$ & $1.16(0.68-1.98)$ \\
\hline Central obesity & $1.04(0.60-1.79)$ & $1.13(0.71-1.81)$ \\
\hline Hypertension & $1.41(0.80-2.50)$ & $0.81(0.48-1.36)$ \\
\hline Dyslipidemia & $0.58(0.37-0.91) £$ & $1.20(0.80-1.79)$ \\
\hline Adverse glycemic profile & $0.61(0.29-1.38)$ & $1.31(0.72-2.39)$ \\
\hline Metabolic Syndrome & $0.76(0.36-1.62)$ & $1.57(0.85-3.28)$ \\
\hline $\begin{array}{l}\text { Hosmer-Lemeshow goodness-of-fit test: } p=0.594 . \text { Area under the ROC curve: } 0.772(95 \% \text { IC } 0.738-0.825) \\
\text { Obs: Outside labor market (unemployed, housewife and student) }\end{array}$ & & \\
\hline
\end{tabular}

may be related to a higher level of female sex hormones. However, controversies about the subject persist since many other factors seem to interfere in this context, such as obesity, race/ethnicity, gynecological history, and social determinants. ${ }^{30}$ In our study, hypertension was strongly correlated with low-educated women, even after adjusting for age (Table 5). A retrospective analysis of large cohorts involving patients of different age ranges describes earlier BP elevations in women, even when adjusting it to the remaining CV risk factors. ${ }^{4,31}$ Our data demonstrate that hypertensive women have a higher prevalence of HDP history, early menopause and previous pregnancies. (Table 3) Thus, additional studies are needed to better establish this relationship.

Regarding risk factors related to lifestyle, our study showed a higher prevalence of sedentary lifestyle in women (Tables 1 and 2), except among those with lower education (Tables 4 and 5). This is an independent CV risk factor and regular physical activities have proved benefits to women in every age range. ${ }^{33}$ The increased prevalence we observed was already described in the Brazilian population ${ }^{34}$, and it signals the magnitude of this public health issue. Regarding women, it is possible to question whether these high levels may be related to social issues, such as double shift of work ${ }^{22}$, but the actual determinants of this difference deserve further investigation.

Smoking was less frequent in women of our sample. However, the difference does not minimize its impact: the prevalence of smoking in women is growing ${ }^{1}$ and there is evidence that smoking women have a higher risk of developing CV diseases compared to smoking men. ${ }^{35}$ Among other outcomes, the risk of acute myocardial infarction seems to be higher ${ }^{36}$ and general CV mortality ${ }^{37}$ seems higher, although additional studies are needed to investigate the cause of these differences.

\section{Risk factors specific to women}

Early menopause and menarche, HDP, gestational $\mathrm{DM}$ and prematurity are independent $\mathrm{CV}$ risk factors in women. ${ }^{2,3,5-7}$ In our study, some of these correlations become evident with significantly higher levels of hypertension in this young population among women who presented HDP, early menopause, and a higher number of pregnancies (Table 3). The same consideration highlights the importance of collecting and analyzing data still unavailable about gestational DM and prematurity in our sample. This also applies to the prevalence of polycystic ovary syndrome. Despite well studied in the literature ${ }^{7,37}$, the association between oral contraceptives use and hypertension was not shown in our sample, possibly due to the shorter period of use. ${ }^{38}$ Regarding the age of menarche, it was not observed different prevalence of hypertension: it is possible that it will happen to the enlargement of the sample and a longer follow-up. 


\section{Social and demographic factors}

In terms of $\mathrm{CV}$ risk, women are particularly vulnerable to situations such as poverty, violence, ${ }^{21}$ and absence of an adequate social protection network. ${ }^{6,39}$ In our study, the most revealing data concerning this scenario are the association between low educational status (a strong indicator of socioeconomic standing) and the prevalence of hypertension, dysglycemia, smoking and metabolic syndrome, which confirms findings from other studies previously developed in Brazil. ${ }^{40}$

In our study sample, $21 \%$ of young women were classified as having a low educational status - either functionally illiterate or basic-level (up to eight years) education. Their adverse cardiovascular risk profile suggests that they need to be main targets of primary care prevention strategies. As for occupational status, only non-consistent and sporadic associations were noticed. Given the large number of women in informal employment (15\% in our sample) and the ever-fluid nature of this indicator, it is clear that a longer follow-up and perhaps a larger sample will be needed to investigate these relationships.

Living in remote locations and belonging to certain ethnicities ${ }^{30,39,40}$ (black, mixed-race and indigenous women) may also affect risk ${ }^{6}$ and thus, in some cases, constitute confounding factors. Our sample, however, is restricted to an urban area; the location of residence does not seem to skew the results. Racial profiles, on the other hand, will have to be further addressed in future analyses, as their possible relationships with our sample's risk profiles have not yet been measured.

On the other hand, data related to the occupation did not reveal consistent correlations. It is possible that the small size of the sample and the fluid nature of this indicator makes it difficult to interpret the data - a longer follow-up of the patients will be needed to determine whether these associations with CV risk are real.

Regarding study limitations, we can highlight that until now only $65 \%$ of the target population living in the coverage area of CSE-Lapa was assessed, being therefore a smaller than expected sample. This may have prevented the achievement of statistical significance of some data. In the specific assessment of women, the lack of information about the prevalence of some specific or more impacting risk factors on women's CV health, such as polycystic ovarian syndrome, gestational diabetes, autoimmune diseases, or psychiatric diseases, as well as specific issues of domestic violence, abuse, and harassment, may have somehow created a bias in our analysis. Data concerning these parameters must be incorporated in future assessments. Similarly, comparisons between impacts of socioeconomic data, especially household income, and CV risks in men and women will also be useful to compare vulnerabilities between these groups.

\section{Conclusions}

We conclude that this population of young women presents an adverse cardiovascular and metabolic risk profile, mainly related to central obesity and sedentary lifestyle, as well as a high prevalence of dyslipidemia, and this scenario is worsened among low-educated women.

\section{Perspectives}

Primary prevention of $\mathrm{CV}$ diseases in young adult women has particularities that must be addressed in order to develop adequate risk assessment strategies and better interventions to avoid unfavorable outcomes. In comparison with men and older women, young women are less diagnosed, less counseled, less treated, and less followed up. In the long term, this can be translated in a higher morbidity. Thus, the point is not only to develop more studies to investigate the risk profiles of this population, but also to empower healthcare professionals to better respond to these specific demands.

LapARC study is currently enrolling participants with the initial objective to trace the $\mathrm{CV}$ risk profile of this young population. This cohort will be followed-up in the long term to identify the main risk factors responsible for future outcomes. This preliminary data has already identified traditional risk factors and socioeconomic determinants greatly affect these young women. Based on these data, we can later guide public policies capable of identifying particularities in the development of $\mathrm{CV}$ diseases in women as well as the elaboration of preventive approaches more suitable for the demands of this population.

\section{Author contributions}

Conception and design of the research: Mello TS, Bica RBS, Muxfeldt ES. Acquisition of data: Mello TS, Klen MS, Barradas FC, Nogueira LA, Ushijima NRM. Analysis and interpretation of the data: Mello TS, Azevedo RB, Bica RBS, Muxfeldt ES. Statistical analysis: Muxfeldt ES. Obtaining financing: Muxfeldt ES. Writing of the manuscript: Mello TS, Kelen MS, Barradas FC, Nogueira LA, Ushijima NRM. 
Critical revision of the manuscript for intellectual content: Azevedo RB, Bica RBS, Muxfeldt ES.

\section{Potential Conflict of Interest}

No potential conflict of interest relevant to this article was reported.

\section{Sources of Funding}

This study was partially funded by Conselho Nacional de Desenvolvimento Científico e Tecnológico (CNPq) and Fundação Carlos Chagas Filho de Amparo à Pesquisa do Estado do Rio de Janeiro (FAPERJ).

\section{Study Association}

This study is not associated with any thesis or dissertation work.

\section{Ethics approval and consent to participate}

This study was approved by the Ethics Committee of the Universidade Estácio de Sá (UNESA/RJ) under the protocol number 50605215.4.0000.5284. All the procedures in this study were in accordance with the 1975 Helsinki Declaration, updated in 2013. Informed consent was obtained from all participants included in the study.

\section{References}

1. World Health Organization. (WHO) 2011. Global Atlas on Cardiovascular Disease Prevention and Control. Mendis S, Puska P, Norrving B editors. World Health Organization (in collaboration with the World Heart Federation and World Stroke Organization). Geneva; 2011.

2. Précoma DB, Oliveira GMM, Simão AF, Dutra OP, Coelho OR, Izar com, et al. Atualização da Diretriz de Prevenção Cardiovascular da Sociedade Brasileira de Cardiologia - 2019. Arq Bras Cardiol. 2019; 113(4):787-891.

3. Cho L, Davis M, Elgendy I, Epps K, Lindley KJ, Mehta PK, et al. Summary of Updated Recommendations for Primary Prevention of Cardiovascular Disease in Women: JACC State-of-the-Art Review. J Am Coll Cardiol. 2020;75(20):2602-18.

4. Ji H, Kim A, Ebinger JE, Niiranen TJ, Claggett BL, Bairey Merz CN, et al. Sex Differences in Blood Pressure Trajectories over the Life Course. JAMA Cardiol. 2020;5(3):255-62.

5. Nielsen PB, Skjøth F, Overvad TF, Larsen TB, Lip GYH. Female sex is a risk modifier rather than a risk factor for stroke in atrial fibrillation should we use a CHA2DS2-VA score rather than CHA2DS2-VASc? Circulation. 2018;137(8):832-40

6. Norris CM, Yip CYY, Nerenberg KA, Clavel MA, Pacheco C, Foulds HJA, et al. State of the science in women's cardiovascular disease: a Canadian perspective on the influence of sex and gender. J Am Heart Assoc. 2019;9:e15634.

7. Barroso WKS, Rodrigues CIS, Bortolotto LA, Mota-Gomes MA, Brandão AA, Feitosa ADM ,et al. Diretrizes Brasileiras de Hipertensão Arterial - 2020. Arq. Bras. Cardiol. 2020; [online] ahead print. DOI: https://doi org/10.36660/abc.20201238.

8. Nobre F, Mion Jr. D, Gomes MAM, Barbosa ECD, Rodrigues CIS, Neves MFT, et al. $6^{\text {a }}$ Diretrizes de Monitorização Ambulatorial da Pressão Arterial e $4^{\mathrm{a}}$ Diretrizes de Monitorização Residencial da Pressão Arterial. Arq Bras Cardiol 2018; 110(5Supl.1):1-29.

9. Faludi AA, Izar MCO, Saraiva JFK, Chacra APM, Bianco HT, Afiune Neto A et al. Atualização da Diretriz Brasileira de Dislipidemias e Prevenção da Aterosclerose - 2017. Arq Bras Cardiol 2017; 109(2Supl.1):1-76.

10. Associação Brasileira para o Estudo da Obesidade e da Síndrome Metabólica. (ABESO). 2019. Diretrizes Brasileiras de Obesidade 2016/ ABESO. Associação Brasileira para o Estudo da Obesidade e da Síndrome Metabólica. 2016. Disponível em https://abeso.org.br/wpcontent/uploads/2019/12/Diretrizes-Download-Diretrizes-Brasileirasde-Obesidade-2016.pdf

11. Wilbur J, Braun LT, Arslanian-Engoren C, Lauver DR, Halloway S. Assessing and addressing cardiovascular risk in young women. Nurs Outlook. 2018;66(3):325-8.

12. Mahajan A, Patni R, Gupta V. Menopause and cardiovascular disease. J Midlife Health. 2019;10(2):55-6.

13. Cavasin MA, Sankey SS, Yu AL, Menon S, Yang XP. Estrogen and testosterone have opposing effects on chronic cardiac remodeling and function in mice with myocardial infarction. Am J Physiol Heart Circ Physiol. 2003; 284(5):H1560-9.

14. Tomaszewski M, Charchar FJ, Maric C, Kuzniewicz R, Gola M, Grzeszczak $\mathrm{W}$, et al. Association between lipid profile and circulating concentrations of estrogens in young men. Atherosclerosis. 2009; 203(1):257-62.

15. Rosano GM, Vitale C, Marazzi G, Volterrani M. Menopause and cardiovascular disease: the evidence. Climacteric. 2007;10 (Suppl 1):19-24.

16. Rossouw JE, Anderson GL, Prentice RL, LaCroix AZ, Kooperberg C, Stefanick ML, et al. for the Writing Group for the Women's Health Initiative Investigators. Risks and benefits of estrogen plus progestin in healthy postmenopausal women: principal results from the Women's Health Initiative randomized controlled trial. JAMA. 2002; 288(3):321-33.

17. Miller V, Naftolin F, Asthana S, Black D, Brinton E, Budoff M, et al. The Kronos Early Estrogen Prevention Study (KEEPS): what have we learned? Menopause. 2019; 26(9):1071-84

18. Dippe Jr T, Cerci RJ. Obesity: a risk marker or an independent risk factor for coronary artery disease? Int J Cardiol Sci, 2020. 33(1):55-6.

19. Kotsis V, Tsioufis K, Antza C, Seravalle G, Coca A, Sierra C, et al. Obesity and cardiovascular risk: A call for action from the European Society of Hypertension working group of obesity, diabetes and the high-risk patient and European association for the study of obesity part B obesityinduced cardiovascular disease, early prevention strategies and future research directions. J Hypertens. 2018; 36(7):1441-55.

20. Almeida RT, Almeida MMG, Araújo T. Abdominal obesity and cardiovascular risk: performance of anthropometric indexes in women. Arq Bras Cardiol, 2009. 92(5):375-80.

21. Chaparro MP, Pina MF, Cardoso L, Santos SM, Barreto SM, Gonçalves LG, et al. The association between the neighborhood social environment and obesity in Brazil: a cross-sectional analysis of the ELSA-Brasil study. BMJ Open, 2019. 9:e026800.

22. Pinto KA, Griep RH, Rotenberg L, Almeida MCC, Barreto RS, Aquino EML. Gender, time use and overweight and obesity in adults: results of the Brazilian longitudinal study of adult health (ELSA-Brasil). PLoS ONE. 2018. 13(3):e0194190.

23. Eickemberg M, Amorim LDAF, Almeida MCC, Pitanga FJG, Aquino EML, Fonseca MJM, et al. Abdominal obesity in ELSA-Brasil (Brazil's Longitudinal Study of Adult Health): construction of a latent gold standard and evaluation of the accuracy of diagnostic indicators. Cienc Saude Colet. 2020. 25(8):2985-98. 
24. Santos RD, Bensenor IM, Pereira AC, Lotufo PA. Dyslipidemia according to gender and race: The Brazilian Longitudinal Study of Adult Health (ELSA-Brasil). J Clin Lipidol. 2016;10(6):1362-8.

25. Wang X, Magkos F, Mittendorfer B. Sex differences in lipid and lipoprotein metabolism: it's not just about sex hormones. J Clin Endocrinol Metab. 2011; 96(4):885-93.

26. Peters SAE, Muntner P, Woodward M. Sex Differences in the Prevalence of, and Trends in, Cardiovascular Risk Factors, Treatment, and Control in the United States, 2001 to 2016. Circulation. 2019;139(8):1025-35.

27. Huebschmann AG, Huxley RR, Kohrt WM, Zeitler P, Regensteiner JG, Reusch JEB. Sex differences in the burden of type 2 diabetes and cardiovascular risk across the life course. Diabetologia. 2019; 62(10):1761-72

28. Peters SA, Huxley RR, Woodward M. Diabetes as a risk factor for stroke in women compared with men: a systematic review and meta-analysis of 64 cohorts, including 775,385 individuals and 12,539 strokes. Lancet. 2014; 383(9933):1973-80.

29. Sillars A, Ho FK, Pell GP, Gill JMR, Sattar N, Gray S, et al. Sex differences in the association of risk factors for heart failure incidence and mortality. Heart. 2020;106(3): 203-12.

30. Alves RF, Faerstein E. Educational inequalities in hypertension: complex patterns in intersections with gender and race in Brazil. Int J Equity Health. 2016;15(1):146.

31. Wenger NK, Arnold A, Bairey Merz CN, Cooper-DeHoff RM, Ferdinand KC, Fleg JL et al. Hypertension Across a Woman's Life Cycle. J Am Coll Cardiol. 2018;71(16):1797-813.

32. Santosa A, Zhang Y, Weinehall L, Zhao G, Wang NH, Zhao Q et al. Gender differences and determinants of prevalence, awareness, treatment and control of hypertension among adults in China and Sweden. BMC Public Health. 2020; 20(1):1763.

33. Colpani V, Oppermann K, Spritzer PM. Association between habitual physical activity and lower cardiovascular risk in premenopausal, perimenopausal, and postmenopausal women: a population-based study. Menopause. 2013; 20(5):525-531.

34. Guthold R, Stevens GA, Riley LM, Bull FC. Worldwide trends in insufficient physical activity from 2001 to 2016: a pooled analysis of 358 population-based surveys with 1.9 million participants. Lancet Global Health. 2018;6: e1077-86

35. Prescott E, Hippe M, Schnohr P, Hein HO, Vestbo J. Smoking and risk of myocardial infarction in women and men: longitudinal population study. BMJ. 1998; 316: 1043-7.

36. Huxley RR, Woodward M. Cigarette smoking as a risk factor for coronary heart disease in women compared with men: a systematic review and meta-analysis of prospective cohort studies. Lancet. 2011;378(9799):1297305 .

37. Gao Z, Chen Z, Sun A, Deng X. Gender differences in cardiovascular disease. Medicine in Novel Technology and Devices. 2019; 4:100025.

38. Liu H, Yao J, Wang W, Zhang D. Association between duration of oral contraceptive use and risk of hypertension: A meta-analysis. J Clin Hypertens (Greenwich). 2017;19(10):1032-41.

39. O'Neil A, Scovelle AJ, Milner AJ, Kavanagh A. Gender/Sex as a Social Determinant of Cardiovascular Risk. Circulation. 2018; 137(8):854-64.

40. Anand SS, Razak F, Davis AD, Jacobs R, Vuksan V, Teo K, et al. Social disadvantage and cardiovascular disease: development of an index and analysis of age, sex, and ethnicity effects. Int J Epidemiol. 2006;35:1239-45. 